\title{
Deltamethrin-induced oxidative stress and biochemical changes in tissues and blood of catfish (Clarias gariepinus): antioxidant defense and role of alpha-tocopherol
}

Kamal A Amin* and Khalid S Hashem

\begin{abstract}
Background: The pyrethroid class of insecticides, including deltamethrin, is being used as substitutes for organochlorines and organophosphates in pest-control programs because of their low environmental persistence and toxicity. This study was aimed to investigate the impact of commonly used pesticides (deltamethrin) on the blood and tissue oxidative stress level in catfish (Clarias gariepinus); in addition to the protective effect of a-tocopherol on deltamethrin induced oxidative stress.

Catfish were divided into three groups, $1^{\text {st }}$ control group include 20 fish divided into two tanks each one contain 10 fish, $2^{\text {nd }}$ deltamethrin group, where Fish exposed to deltamethrin in a concentration $(0.75 \mu \mathrm{g} / \mathrm{l})$ and $3^{\text {rd }}$ Vitamin $\mathrm{E}$ group, Fish exposed to deltamethrin and vitamin $\mathrm{E}$ at a dose of $12 \mu \mathrm{g} / \mathrm{l}$ for successive 4 days.

Serum, liver, kidney and Gills were collected for biochemical assays. Tissue oxidative stress biomarkers malondialdhyde (MDA) and catalase activity in liver, kidney and gills tissues, serum liver enzymes (ALT and AST), serum albumin, total protein, urea and creatinine were analysed.

Results: Our results showed that $48 \mathrm{~h}$. exposure to $0.75 \mu \mathrm{g} / \mathrm{l}$ deltamethrin significantly $(p<0.05)$ increased lipid peroxidation (MDA) in the liver, kidney and gills while catalase activity was significantly decreased in the same tissues. This accompanied by significant increase in serum ALT, AST activity, urea and creatinine and a marked decrease in serum albumin and total proteins.

Conclusions: It could be concluded that deltamethrin is highly toxic to catfish even in very low concentration $(0.75 \mu \mathrm{g} / \mathrm{l})$. Moreover the effect of deltamethrin was pronounced in the liver of catfish in comparison with kidneys and gills. Moreover fish antioxidants and oxidative stress could be used as biomarkers for aquatic pollution, thus helping in the diagnosis of pollution. Adminstration of $12 \mu \mathrm{g} / \mathrm{l}$ a-tocopherol restored the quantified tissue and serum parameters, so supplementation of a-tocopherol consider an effective way to counter the toxicity of deltamethrin in the catfish.
\end{abstract}

Keywords: Deltamethrin, Clarias gariepinus, Egypt, Oxidative biomarkers, Catalase, Malondialdhyde, a-tocopherol

\footnotetext{
* Correspondence: kaamin10@yahoo.com

Faculty of Veterinary Medicine, Department of Biochemistry, Beni Suef University, 62511 Beni Suef, Egypt
}

\section{Biomed Central




\section{Background}

For centuries, pesticides have been used in agriculture to enhance food production by eradicating unwanted insects and controlling disease vectors. Among common pesticides are organophosphorus compounds which are widely used in agriculture, medicine and industry. The main advantages of pyrethroids that made it successively replacing organophosphrus pesticides are their photostability, high effectiveness even in low concentration, easily disintegration, and low toxicity in birds and mammals [1].

Fish and various other aquatic organisms are extremely susceptible to pyrethroids as the $96 \mathrm{~h}$ Lc50 value determined in laboratory tests, generally lies below $10 \mu \mathrm{g} / \mathrm{l}$. In addition, deltamethrin is based on pyrethroids that have established significantly lower rates of metabolism and removal in fish than those recorded for birds and mammals [2].

Effluents of agricultural and industrial processes contain highly toxic chemicals like pesticides that lead to pollution of aquatic environments including rivers, ponds and lakes. The accumulation and persistence of insecticide and pesticides in the aquatic environment constitute a threat to biological life, as witnessed by the chronic and acute poisoning of fish and other aquatic organisms [3].

Deltamethrin has very good residual activity for outdoor uses and for indoor uses; it has a high toxicity to fish under laboratory environment. However, in field conditions under normal conditions of use, fish may not harmed. Deltamethrin had an impact on aquatic herbivorous insects. This impact led to an increase of algae.

The World Health Organisation reported that roughly 3 million cases of pesticide poisoning occur annually that result in 22000 deaths worldwide. Many of these chemicals are mutagenic [4] linked to the development of cancers or may lead to development deficits [5].

Clarias species are air breathing fishes due to the presence of accessory assistant respiratory organs beside the gills enabling it to survive for long time outside the water, otherwise debilitating hypoxic environments [6]. Catfish Clarias is freshwater, belonging to the genus Clarias. There are 32 species of catfish belonging to genus Clarias are known in Africa. Clarias lazera and Clarias gariepinus are the most popular members of the inland water fishes found in Egypt.

Clarias lazera is known locally as karmout and is commonly found in Lake Nasser and all Nile branches and streams [7]. These species are tolerant to a wide range of water and laboratory conditions and has detritivorous behaviour. This means that the fish can be in contact with xenobiotics from different ways of interacting with algae from stone or sediment. These characteristics make this particular species an interesting model for ecotoxicological and biochemical studies. Moreover Catfish are valuable bio-indicators of contamination because of their large distribution, being open swimmers, capacity to react against ecological pollution and food source for human.

The long-term biological hazards associated with the use of organochloride, organophosphate and carbamate pesticides propelled the introduction of a new generation of pesticides with a lesser degree of persistence. In this direction, the use of pyrethroids as insecticidal and antiparasitic formulations has markedly increased as a viable substitute and account for over $30 \%$ of insecticides used globally [8].

Deltamethrin $\quad[((\mathrm{s})$-a-cyano-3-phenoxybenzyl(R1-R2)-3(2,2 dibromvinyl)-2,2 dimethylcyclo-propancarboxylate] is one of the most important widely used pyrethroids pesticide and insecticides, since the application of pyrethroid as insecticide and antiparasitary preparations has been accepted on a large scale for agricultural purposes and very markedly increased during last 10-15 years; even though it is already known that this insecticide is highly toxic to fish and various other aquatic organisms [9].

The presence of low deltamethrin concentration in water has sublethal effects such as altered energy metabolism and ionic regulation. It is a synthetic type two of pyrethroids, which has a wide range of application in industrial and agricultural purposes. It is also used as an alternative pesticide in animal health, in vector control, and in public health [10].

Among the most commonly used biomarkers, those related to oxidative stress assume an important position, being frequently used both in environmental monitoring and laboratory assays [11].

Rates or amounts of reactive oxygen species (ROS) production can be increased by the presence of a wide range of natural and man-made xenobiotics [12].

The stimulation of free radical production, induction of lipid peroxidation, and disturbance of the total antioxidant capability of the body are mechanisms of toxicity for most pesticides, including organochlorines and pyrethroids [13]. Consequently, the antioxidant defences are potentially interesting biomarkers to pesticides while enhanced lipid peroxidation, a consequence of oxidative deterioration of membrane lipids, is generally referred to an index of oxidative stress. Moreover, ROS alter protein structure or function and Amino acid side-chains can be irreversibly modified into aldehyde or ketone groups (carbonylation) which can lead to protein aggregation, inactivation or degradation, these changes in protein carbonylation process are a biochemical perturbation resulting from oxidative stress [14].

Few reports have demonstrated the induction of oxidative stress by pyrethroids, such as cypermethrin and fenvalerate [15], while the effect of deltamethrin on catfish have not been investigated. Induction of oxidative stress is one 
of the main mechanisms of many pesticides action [13]. The damage to membrane lipids, protein and DNA is the endpoint biomarker of oxidative stress-inducing effects of pesticides [16]. Various adaptive and compensatory responses are also induced as a result of exposure to deltamethrin in fish [17].

$\alpha$-tocopherol, a fat-soluble vitamin, is a major antioxidant, responsible for terminating free radical chain reactions that result from the oxidation of polyunsaturated fatty acids (PUFA) [18]. Therefore, it was suggested an increased amount of $\alpha$-tocopherol supplementation to inhibit cellular lipid peroxidation of PUFA.

In order to protect the tissue from oxidant injury, antioxidant enzymes are also present in the biological system. Blomhoff [19] reported that when animals are exposed to a dietary oxidative stress, they react with compensatory induction of endogenous antioxidants. Supplementation of dietary components like vitamin $\mathrm{E}$ [tocopherols and tocotrienols) and vitamin C, etc. lowered lipid peroxidation, protein oxidation and the incidence of various morbidities or mortalities; induced catalase activity, reduced the oxidative stress in rat.

The contamination of aquatic ecosystem by pesticides has gained increasing attention in recent decades. The acute and chronic exposure and accumulation of these chemicals can result in tissue burdens that produce adverse effects not only in the exposed organisms, but also organisms including human beings; therefore, it seems essential to study detrimental effects of such hazardous pollutants so as to formulate the strategies for safe guarding aquatic organisms.

The present study was designed to assess the effect of two doses of deltamethrin on several biochemical parameters on serum and tissues of catfish (Clarias gariepinus) to establish this species as a model for biochemical studies. Also, we aimed to investigate the effects of deltamethrin on some oxidative biomarkers (MDA and catalase activities) and some serum biochemical parameters, alanine transaminase (ALT), aspartate transaminase (AST), total protein, albumin, urea and creatinine. In order to better understand fish response to deltamethrin exposure and try to use $\alpha$-tocopherol in order to restore the alteration of the changes in the oxidative and biochemical parameters which are dysregulated by deltamethrin.

\section{Materials and methods Material}

Fish rearing and management

A total of 40 immature channel catfish of both sexes were collected from different localities of El-Ebrahemia channel average weighted $100 \pm 5$ g were reared in water aquaria for one week for acclimation before the beginning of the experiment [15]. The water temperature about $22^{\circ} \mathrm{C}-23^{\circ} \mathrm{C}$ and $\mathrm{pH}$ level kept at $7.6 \pm 0.4$. Water was supplied with oxygen by air pump. The photoperiod was a 12-h light to 12-h dark cycle and the fish were fed on commercial ration at ratio of $3 \%$ of body weight/day.

\section{Chemicals}

The following chemicals were used: Deltamethrin were purchased as a commercial product (Butox) $50 \mathrm{mg} / \mathrm{ml}$. $\alpha$-tocopherol were purchased as a solution of $10 \%$ from the El Naser Pharmaceutical Company (Cairo-Egypt).

\section{Methods}

This experimental research was approved by the Committee of Scientific Ethics at Beni Suef University, faculty of veterinary medicine, Biochemistry department and consistent with its guidelines.

\section{Experimental design and Fish grouping}

Catfish were divided into three groups, as follows:

Control group: 20 fish divided into two tanks each one contain 10 fish. Fish were kept in 10 liters of de-chlorinated water. Water was changed once daily.

Deltamethrin group: Fish exposed to deltamethrin in a concentration of $0.75 \mu \mathrm{g} / \mathrm{l}[16,17,20]$ for 48 hours as follow, 10 fish were put in 10 liters of de-chlorinated water tank contains deltamethrin in concentration of $0.75 \mu \mathrm{g} / \mathrm{l}$. To keep a constant concentration of deltamethrin, water was sucked daily and the tank was supplied by water with deltamethrin in the same concentration daily for 2 days.

Vitamin E group: Fish exposed to deltamethrin in a concentration $(0.75 \mu \mathrm{g} / \mathrm{l})$ for 48 hours as mentioned before. In the third day, fish were supplied by 10 liters of water contain vitamin $\mathrm{E}$ at a dose of $12 \mu \mathrm{g} / \mathrm{l}$ for successive 4 days. To keep a constant concentration of deltamethrin, water was sucked daily and the tank was supplied by water with vitamin $\mathrm{E}$ in the same concentration daily for 4 days.

\section{Sampling and tissue preparation}

Serum samples At the end of the experiment (1 week post administration of chemicals) fish were caught by a net and blood collected from the caudal peduncle then transferred to clean dry centrifuge tubes then left for $2 \mathrm{~h}$ for clotting and centrifuged at $3000 \mathrm{rpm}$ for $15 \mathrm{~min}$, followed by serum separation and storage in deep freeze till biochemical analysis.

Tissue samples Liver; kidneys and gills of scarified fish were rapidly removed, cleaned from any extraneous materials and immediately perfused with saline. The tissues were homogenised in phosphate buffer $(0.1 \mathrm{M} \mathrm{pH}$ 7.4).the homogenate was filtered and centrifuged at 1 $500 \mathrm{rpm}$ for $20 \mathrm{~min}$.The supernatant was stored in deep freeze until biochemical analysis. 


\section{Biochemical analysis of serum and tissue}

Serum ALT and AST were measured colourimetrically according to method described by Reitman et al. [21] using kits purchased from Diamond Diagnostic (Cairo, Egypt). Serum total protein and albumin were measured according to Lubran [22] and Doumas et al. [23], respectively. Also measurements of serum urea [24] and serum creatinine [25] were considered using spectrophotometer (Hitachi 2000).

Lipid peroxide was measured in tissues according to method of Satoh [26] that based on the ability of thiobarbituric acid (TBA) to reacts with malondialdhyde (MDA) in acidic medium at temperature of $95^{\circ} \mathrm{C}$ for $30 \mathrm{~min}$ to form TBA reactive product the absorbance of the resultant pink product can be measured at $534 \mathrm{~nm}$. Tissue catalase activities were measured according to Aebi et al. [27].

\section{Statistical analysis}

The obtained data were statistically analyzed by ANOVA test using PC-STAT Statistical programs and data were reported as mean \pm SEM.

\section{Results}

The results are summarised in tables and figure as follows:

Table 1: demonstrates that deltamethrin $(0.75 \mu \mathrm{g} / \mathrm{l})$ significantly increased the activities of AST and ALT, while significantly decreased the level of serum total protein and albumin compared to control group. In addition exposure to $\alpha$-tocopherol significantly improved ALT and AST activities, while significantly increase concentration of serum total protein and albumin in comparison with deltamethrin group. $\alpha$-tocopherol alleviated the toxicity and negative effect of deltamethrin on the activities of the measured enzymes.

Table 2: shows that MDA level (LPO) was significantly increased, in liver, kidney and gills of fish treated with deltamethrin in the same dose. Exposure to $\alpha$-tocopherol caused significant reduction in the elevated MDA and maintain to its normal values in liver, kidney and gills MDA in comparison with deltamethrin group and control.

Table 3: illustrates that catalase activities were significantly increased, in liver, kidney and gills in fish treated with deltamethrin when compared to control group. Exposure to $\alpha$-tocopherol caused significant elevated the dysregulation of catalase activity in Liver, kidney and gills in comparison with deltamethrin group.

Figures 1 and 2 show that serum urea and creatinine was significantly increased in catfish treated with deltamethrin, while exposure to $\alpha$-tocopherol decreased and maintained these levels to the normal values.

\section{Discussion \\ Effect of deltamethrin on liver function and its modulation by a-tocopherol}

The evaluation of serum AST and ALT activities, T. proteins, albumin and hepatic MDA level and catalase activity bears significance with respect to the evaluation of the effects of pesticides on the liver, therefore their toxicity [28].

The current results showed significant increase in plasma ALT and AST activities (Table 1). The increase in activity of these enzymes in plasma is indicative for liver damage and thus causes alteration in liver function [29,30]. In addition, El-Demerdash et al. [15] found that cell damage exhibited good correlation with the enzyme leakage. Hence, cellular damage caused by toxic substances is frequently accompanied by increasing cell membrane permeability.

The decrement of plasma total protein, albumin (Table 1) comes in agree with Yousef et al. [29,30] and El-Demerdash et al. [15]. This decrease in plasma protein could be attributed to changes in protein and free amino acids metabolism and their synthesis in liver. Also the observed decreases in plasma proteins could be attributed to the damaging effect of deltamethrin on liver c ells as confirmed by increasing in the activities of ALT and AST.

\section{Effect of deltamethrin on renal function tests and its modulation by a-tocopherol}

Blood urea levels were significantly elevated in deltamethrin exposed group in comparison with control group (Figure 1), this elevation may be due to correlation between urea and increased protein catabolism or from more efficient conversion of ammonia to urea as a result of increased synthesis of enzyme involved in urea production.

Table 1 Effects of deltamethrin $(0.75 \mu \mathrm{g} / \mathrm{l})$ and a-tocopherol on serum liver enzymes activities in catfish

\begin{tabular}{|c|c|c|c|c|}
\hline Groups & ALT (IU/I) & AST (IU/I) & T. proteins (g/dl) & Albumin (g/dl) \\
\hline Controls & $31.97 \pm 1.82^{(a)}$ & $20.99 \pm 3.43^{(a)}$ & $4.55 \pm 0.13^{(a)}$ & $1.83 \pm 0.05^{(a)}$ \\
\hline Deltamethrin $(0.75 \mu \mathrm{g} / \mathrm{l})$ & $61.58 \pm 5.66^{(a)}$ & $55.67 \pm 7.54^{(b)}$ & $3.65 \pm 0.2^{(b)}$ & $1.46 \pm 0.08^{(b)}$ \\
\hline a-tocopherol $(12 \mu \mathrm{g} / \mathrm{l})$ & $26.80 \pm 3.40^{(a)}$ & $11.97 \pm 1.22^{(\mathrm{a})}$ & $4.66 \pm 0.39^{(a)}$ & $1.91 \pm 0.14^{(\mathrm{a})}$ \\
\hline
\end{tabular}

ALT, alanine transaminase activitiy.

AST, aspartate transaminase activitiy.

Values are expressed as means \pm SEM.

Means with different supercripts are significantly different $(p<0.05)$, while means with the same superscripts indicate non-significant changes. 
Table 2 Effects of deltamethrin and a-tocopherol on liver, Kideny and gill malondialdhyde levels

\begin{tabular}{llll}
\hline Groups & Liver MDA (nmol/g tissue) & Kidney MDA (nmol/g tissue) & Gill MDA (nmol/g tissue) \\
\hline Controls & $21.49 \pm 0.38^{(\mathrm{a})}$ & $12.91 \pm 0.23^{(\mathrm{a})}$ & $8.58 \pm 0.15^{(\mathrm{a})}$ \\
Deltamethrin $(0.75 \mu \mathrm{g} / \mathrm{l})$ & $33.10 \pm 1.79^{(\mathrm{b})}$ & $19.87 \pm 1.07^{(\mathrm{b})}$ & $13.24 \pm 0.71^{(\mathrm{b})}$ \\
a-tocopherol $(12 \mu \mathrm{g} / \mathrm{l})$ & $21.59 \pm 0.77^{(\mathrm{a})}$ & $12.93 \pm 0.46^{(\mathrm{a})}$ & $8.64 \pm 0.31^{(\mathrm{a})}$ \\
\hline
\end{tabular}

MDA, malondialdhyde.

Values are expressed as means \pm SEM.

Means with different superscripts are significantly different $(p<0.05)$, while means with the same superscripts indicate non-significant changes.

The high levels of blood urea and creatinine (Figure 2) result either from increased breakdown of tissue or dietary or impaired excretion or increased synthesis or decreased urinary clearance by the kidney or decreased degradation of these compounds [31]. The present data suggest that polluted fish adept glomerular dysfunction rather than tubular insufficiency as blood levels of urea and creatinine depend largely on glomerular function.

In consistent with these explanations of decreased total protein level with deltamethrin administration, urea is the end product of protein catabolism in mammals but in fish ammonia is the end products of protein, So the marked increase in blood urea nitrogen could be attributed to impaired excretion of urea through kidney and this explanation is supported by increasing blood creatinine level which is more sensitive and specific indicator of impaired kidney function [32].

\section{Effect of deltamethrin on liver, kidneys and gills oxidative} stress and its modulation by a-tocopherol

Fish gills, kidneys and liver are critical organs for their respiratory, osmoregulatory and excretory functions. Respiratory distress is one of the early symptoms of pesticide poisoning. A high rate of absorption of deltamethrin through gills also makes fish a vulnerable target of its toxicity [33].

Some studies indicated that exposure to lethal concentrations of deltamethrin caused destructive effect in the gill, kidney and liver tissues of $C$. carpio. The catfish gill is a multipurpose organ that plays role in water gas exchange, osmotic and ionic regulation, acid-base balance and elimination of nitrogenous wastes so, Gill and kidney tissues alterations may result in severe functional problems, ultimately leading to the death of fish.
A single $48 \mathrm{~h}$. exposure to deltamethrin-induced oxidative stress in all the tissues, as depicted by elevated levels of MDA in tissues. Deltamethrin is known to alter cell metabolism in various ways, with a potential genotoxic risk, including DNA damage and micronucleus induction in freshwater fish [34].

The present findings implicate a role of oxidative stress and free radical formation in these effects. Studies in rodents have demonstrated that absorbed deltamethrin is readily metabolised and excreted; elimination is achieved within 2-4 days. The major metabolic reactions ascribed to deltamethrin metabolism are oxidations mediated by the microsomal monooxygenase system.

The degradation pathways in cows, poultry, and fish are almost similar to those in rodents. However, comparative in vivo and in vitro metabolic studies have shown that fish have a lower capacity to metabolize and eliminate pyrethroid insecticides [35]. This is reflected in the present investigation, where deltamethrin induced peroxidative damage in all the tissues and the gills in particular during a short-term subacute exposure regimen. The extent of MDA is determined by the balance between the production of oxidants and the removal and scavenging of those oxidants by antioxidants [36].

Gills are the primary sites for the absorption of deltamethrin. It is, therefore, obvious that we noted a high level of MDA coupled with depletion of antioxidant enzymes in the gills. Lipid peroxidation has been extensively used as a biomarker of oxidative stress [37].

MDA are produced by LPO and considered as indicators of oxidative stress, which results from the free radical damage to membrane components of cells.

Fish exposure to deltamethrin-induced oxidative stress in all tissues, as depicted by elevated levels of MDA in tissues [Table 2). Deltamethrin is known to alter cell

Table 3 Effects of deltamethrin and a-tocopherol on Liver, kidney and gill catalase activity in catfish

\begin{tabular}{llll}
\hline Groups & Liver catalase $(\mathbf{u} / \mathbf{g}$. tissue) & Kidney catalase $(\mathbf{u} / \mathbf{g}$ tissue) & Gill catalase (u/g tissue) \\
\hline Controls & $0.26 \pm 0.012^{(\mathrm{a})}$ & $0.35 \pm 0.01^{(\mathrm{a})}$ & $0.33 \pm 0.009^{(\mathrm{a})}$ \\
Deltamethrin $(0.75 \mu \mathrm{g} / \mathrm{l})$ & $0.16 \pm 0.019^{(\mathrm{b})}$ & $0.29 \pm 0.011^{(\mathrm{b})}$ & $0.25 \pm 0.012^{(\mathrm{b})}$ \\
a-tocopherol $(12 \mu \mathrm{g} / \mathrm{l})$ & $0.27 \pm 0.021^{(\mathrm{a})}$ & $0.35 \pm 0.012^{(\mathrm{a})}$ & $0.34 \pm 0.014^{(\mathrm{a})}$ \\
\hline
\end{tabular}

(u/g.) Unit/gm tissue.

Values are expressed as means \pm SEM (standard error mean).

Means with different superscripts are significantly different $(p<0.05)$, while means with the same superscripts indicate non-significant changes. 


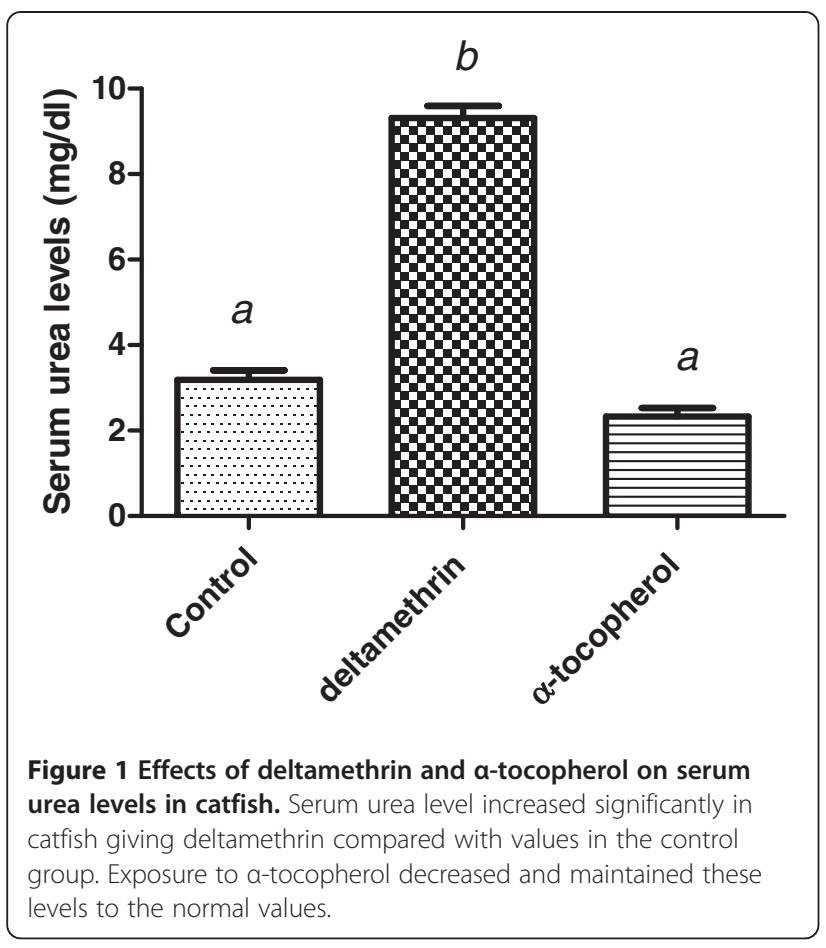

metabolism in various ways, with potential genotoxic risk, including DNA damage and micronucleus induction. Comparative in vivo and in vitro metabolic studies have shown that fish have a lower capacity to metabolise and eliminate pyrethroid insecticides [35].

In the present study exposure of catfish to $0.75 \mu \mathrm{g} / \mathrm{l}$ concentration of deltamethrin (Table 2) shows a marked

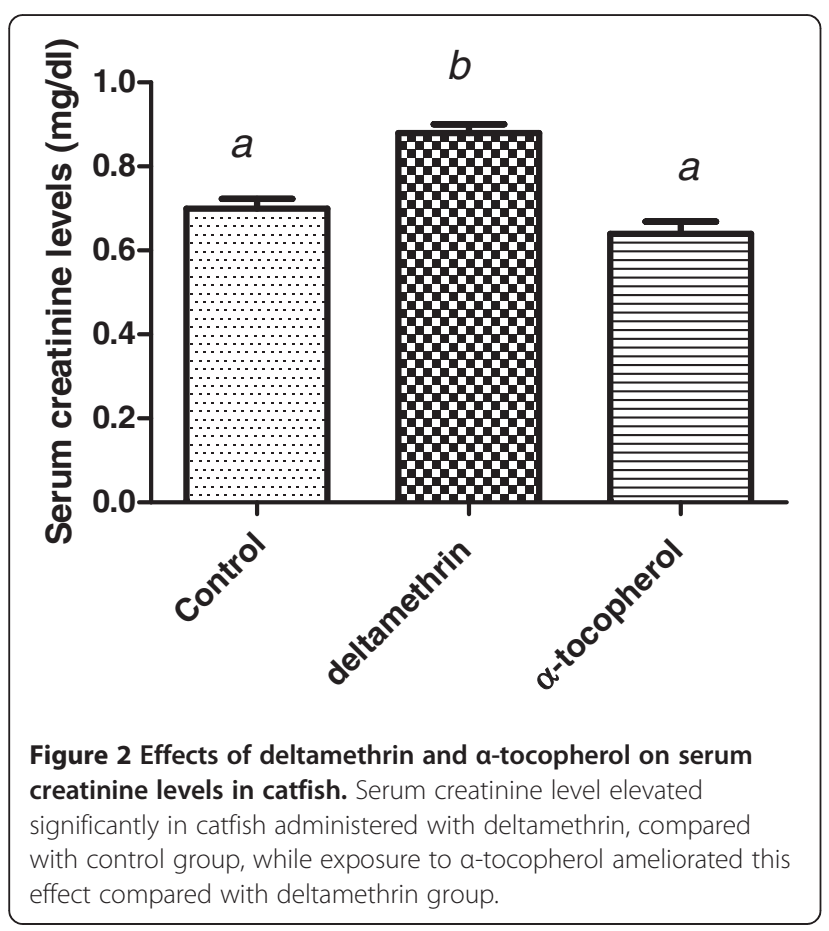

increase in MDA in the liver, kidney and gill [38,39]. This marked increase could be attributed to the ability of deltamethrin for free radical formation.

Catalase activity was significantly reduced in the deltamethrin group when compared to control one (Table 3) and this in agreement with Pandey et al. [38]. This significant reduction could be attributed to the influx of super oxide radicals, which have been reported to decrease CAT activity.

The current results showed that deltamethrin is highly toxic to fish even in low concentration [0.75 $\mu \mathrm{g} / \mathrm{l})$ while sublethal concentration of deltamethrin was [1.5 $\mu \mathrm{g} / \mathrm{l})$ as reported by Svobodova et al. [40]. This highly toxic effect of deltamethrin in fish is due to the high rate of absorption of deltamethrin through the gills and lack of fish to the enzymes responsible for metabolism and detoxification of deltamethrin [17].

The decreased CAT activities, total proteins and albumin, while increased MDA level in liver as well as increased serum AST and ALT activities suggest that deltamethrin produces hepatic dysfunction. The pathogenesis may be through free radical formation where deltamethrin undergoes metabolism in the liver via hydrolytic ester cleavage and oxidative pathways by the cytochrome P450 microsomal enzyme system which probably decreased the P450 contents in liver that may causes in oxidative stress producing depletion of CAT activity and increased the level of MDA leading to hepatic degeneration and necrosis [41].

$\alpha$-tocopherol considered the principal antioxidant defence against lipid peroxidation in cell membranes of mammals. The most important role of $\alpha$-tocopherol in tissues seems to be the protection of membrane PUFA against the effects of oxygen radicals It inhibits peroxidation of membrane lipids by scavenging lipid peroxyl radicals, and is converted into a tocopheroxyl radical as a consequence [18]. $\alpha$-tocopherol selectively blocks the pyrethroid-modified sodium channel in a dosedependent manner without affecting normal sodium channels. Moreover $\alpha$-tocopherol maintained the activities of membrane-bound enzymes at near normal values, and thus preserving mitochondrial membrane integrity and protected some enzyme activities from oxidation by free radicals [42].

Vitamin E dietary supplementation decreased the susceptibility to lipid peroxidation in rat tissues and peroxidation of rat liver microsomes induced by Fe/ascorbate [18]. The malondialdehyde production in tissue homogenates is used as an estimate of lipid peroxidation.

The protective effect of $\alpha$-tocopherol against deltamethrin that induced elevation of serum and tissues MDA, observed in this study, was harmony with its antioxidant activity and might also be relevant to its prophylactic and therapeutic effect against environmental pollutants. 
ROS have been implicated in the toxicology of pyrethroids, so the protective effect of $\alpha$-tocopherol, observed in our study, could be important for protecting the different tissues against the oxidative injury following the use of deltamethrin. So fish fed a low level of dietary $\alpha$-tocopherol failed to counter the stress of deltamethrin pollution.

The results in Table 2 showed that lipid peroxidation in liver was higher than MDA in kidneys and gills also catalase activity were reduced in liver in comparison with kidneys and gills respectively this is due to the fact, that liver is the main organ for metabolism and detoxification of deltamethrin $[16,43]$, demonstrating that the toxicity of deltamethrin was pronounced in the liver of catfish in compare with kidneys and gills this indicate that liver is the main affected organ by pollution and the most sensitive for oxidative stressors.

In general, antioxidant enzyme activity in kidney and gills was less evident than in liver. Oxidative stress indices (levels of MDA) were significantly higher in liver, despite a trend to increased values were manifested in the remaining tissues. In short, deltamethrin-induced stress responses in different tissues were reflected in the oxidative stress indices and liver function parameters. Those parameters may use as biomarkers for monitoring residual pharmaceuticals in aquatic environment, However more detailed experiments in laboratory need to be performed in the future.

Alterations in serum urea, creatinine (Figures 1 and 2), renal MDA and catalase are encountered primarily in dysfunction and injure of the kidneys, while gill MDA and catalase are markers of gill function.

The hepatic antioxidant enzyme (CAT) activity was inhibited significantly at concentrations $(0.75 \mu \mathrm{g} / \mathrm{l})$ of deltamethrin. Meanwhile, the antioxidant enzyme activity was significantly inhibited in kidney and gills of fish. Moreover there was significant higher MDA level in hepatic, renal and Gill tissues in deltamethrin group compared with control. In short, concentrations of $(0.75 \mu \mathrm{g} / \mathrm{l})$ deltamethrin could induce obvious impacts on different organs in fish, and could affect seriously the health status of fish.

This biochemical information will be helpful in assessing the impact of deltamethrin toxicity to freshwater fish as well as in developing a sensitive biomarker of aquatic pollution caused by the excessive release of deltamethrin into the freshwater.

Alterations of lipid peroxidation and catalase activity after deltamethrin exposure suggesting the use of these antioxidants as a potential biomarker of toxicity associated with contaminant exposure in freshwater catfish.

Application of specific concentration of heavily used deltamethrin with the Egyptian catfish that grow in many water areas, using serum and tissues biochemical makers for monitoring pollution and treatment with natural vitamin $\mathrm{E}$ as antioxidant through water and making sure it taken by catfish not forming a film, provides novelty to our study.

\section{Conclusions}

It could be concluded that, deltamethrin is highly toxic to catfish even in very low concentration $(0.75 \mu \mathrm{g} / \mathrm{l})$ in spite of major researches where they reported that deltamethrin is safe for living organisms at sublethal concentration $(1.5 \mu \mathrm{g} / \mathrm{l})$.

Moreover our results recommended that oxidative stress may, in part, be contributing to deltamethrininduced hepatic, renal and gill damage. It may provide an indication of aquatic pollution load of deltamethrin in the affected catfish population, so help in the diagnosis of the pollution. Also our results indicated that $\alpha$-tocopherol could modulate and diminish the adverse effects of deltamethrin on most of biochemical parameters, lipid peroxidation and enzymatic activities if used in low concentration $(12 \mu \mathrm{g} / \mathrm{l})$. Also, deltamethrin produced oxidative stress in fish gill more than liver and kidney both at catalase activity and MDA levels.

\section{Competing interests}

The authors declare that they have no competing interests.

\section{Acknowledgements}

This study was supported by fund from Beni Suef University, Beni Suef, Egypt. We thanks Prof. Dr. Abd Elsalam SA biochemistry department and Prof Dr. Ismail M Pharmacology Department for their advice and support

\section{Authors' contributions}

$\mathrm{KA}$ and $\mathrm{KH}$ carried out experimental work; biochemical and statistical analysis, interpretation and discussion of the results wrote the paper, related to their part of the work. All authors perform drafting, read and approved the final manuscript.

Received: 28 September 2011 Accepted: 26 April 2012

Published: 26 April 2012

\section{References}

1. Bradbury SP, Coats JR: Comparative toxicology of the pyrethroid insicticides. Rev Environ Contam Toxicol 1989, 108:133-177.

2. Bradbury SP, Coats JR: Toxicokinetic and toxicodynamics of pyrethroid insecticides in fish. Environ Toxicol Chem 1989, 8:373-380.

3. Langston WJ: Heavy Metals in the Marine Environment. Boca Raton, Florida: CRC Press; 1990:101-122.

4. Garaj-Vrhovac V, Zeljezic D: Evaluation of DNA damage in workers occupationally exposed to pesticides using single cell gel electrophoresis [SCGE) assay. Pesticide genotoxicity revealed by comet assay. Mutat Res 2000, 469(2):279-285.

5. Arbuckle TE, Sever LE: Pesticide exposures and fetal death: a review of the epidemiological literature. Crit Rev Toxicol 1998, 28:229-270.

6. Olson KR, Ghosh TK, Roy PK, Munshi JS: Microcirculation of gills and accessory respiratory organs of the walking catfish Clarias batrachus. Anat Rec 1995, 242:383-399.

7. Dowidar NM, Zaki MI, Abdalla A: Sexual maturity, gonadal cycle and fecundity of Clarias lazera in Lake Manzalah. Egypt First Int Conf App Sci, Zagazig Univ 1985, 4:225-245.

8. Prasamthi K, Muralidhara, Rajini PS: Fenvalerate-induced oxidative damage in rat tissues and its attenuation by dietary sesame oil. Food Chem Toxicol 2005, 43:299-306. 
9. Mittal PK, Adak T, Sharma VP: Comparative toxicity of certain mosquitocidal compounds to larvivorous fish Poecilia reticulate. Indian $\lrcorner$ Malariol 1994, 31:43-47.

10. Köprücü SS, Köprücü K, Ural MS: Acute toxicity of the synthetic pyrethroid deltamethrin to fingerling European catfish, Silurus glanis L. Bull Environ Contam Toxicol 2006, 76:59-65.

11. Pandey S, Parvez S, Sayeed I, Haque R, Bin-Hafeez B, Raisuddin S: Biomarkers of oxidative stress: a comparative study of river Yamuna fish Wallago attu [BI. \& Schn.). Sci Total Environ 2003, 309:105-115.

12. Livingstone DR: Contaminant-stimulated reactive oxygen species production and oxidative damage in aquatic organisms. Mar Pollut Bull 2001, 42:656-666.

13. Abdollahi M, Ranjbar A, Shadnia S, Nikfar S, Rezaie A: Pesticides and oxidative stress: a review. Med Sci Monit 2004, 10:RA141-1471.

14. McDonagh B, Tyther R, Sheehan D: Redox proteomics in the mussel, Mytilus edulis. Mar Environ Res 2006, 62:S101-S104.

15. El-Demerdash FM, Yousef Ml, Kedwany FS, Baghdadi HH: Role of alpha-tocopherol and B-carotine in ameliorating the fenvalerate induced changes in oxidative stress, hemato-biochemical parameters, and semen quality of male rats. J Environ Sci Health B 2004, 39:443-459.

16. Parvez S, Raisuddin S: Protein carbonyls: novel biomarkers of exposure to oxidative stress inducing pesticides in freshwater fish Channa punctata (Bloch). Environ Toxicol Pharmacol 2005, 20:112-117.

17. Sayeed I, Parvez S, Pandey S, Hafeez B, Haque R, Raisuddin S: Oxidative stress biomarkers of exposure to deltamethrin in freshwater fish. Channa punctatus Bloch. Ecotox Environ Saf 2003, 56:95-301.

18. Ciocoiu M, Badescu M, Paduraru I: Protecting antioxidative effects of vitamins $E$ and $C$ in experimental physical stress. J Physiol Biochem 2007, 63:187-194.

19. Blomhoff R: Dietary antioxidants and cardiovascular disease. Curr Opin Lipidol 2005, 16:47-54.

20. Datta M, Kaviraj A: Ascorbic acid supplementation of diet for reduction of deltamethrin induced stress in freshwater catfish Clarias gariepinus. Chemosphere 2003, 53:883-888.

21. Reitman S, Frankel S: Colorimetric estimation of serum transaminases. Am J Clin Pathol 1957, 28:56-63.

22. Lubran MM: The measurement of total serum proteins by the Biuret method. Ann Clin Lab Sci 1978, 8:106-110.

23. Doumas BT, Watson WA, Biggs HG: Albumin standards and measurement of serum albumin with bromocresol green. Clin Chem Acta 1971, 31:87-96.

24. Chaney AL, Marbach EP: Modified reagents for determination of urea and ammonia. Clin Chem 1962, 8:130-132

25. Perakis N, Wolff CM: Kinetic approach for the enzymic determination of creatinine. Clin Chem 1984, 30:1792-1796.

26. Satoh K: Serum lipid peroxides in cerebrovascular disorders determined by a new colorimetric method. Clin Chim Acta 1978, 90:37-43.

27. Aebi H: Catalase in vitro. Methods Enzymol 1984, 105:121-126.

28. Eraslan G, Bilgili A, Essiz D, Akdogan M, Sahindokuyucu F: The effects of deltamethrin on some serum biochemical parameters in mice. Pesticide Biochem Physiol 2007, 87:123-130

29. Yousef Ml, Awad TI, Mohamed EH: Deltamethrin-induced oxidative damage and biochemical alterations in rat and its attenuation by Vitamin E. Toxicology 2006, 227:240-247.

30. Yousef Ml, El-Demerdash FM, Kamel Kl, Al-Salhin KS: Changes in some haematological and biochemical indices of rabbit induced by isoflavenes and cypermethrin. Toxicology 2003, 189:223-234.

31. Adham KG, Ibrahim HM, Hamed SS, Saleh RA: Blood chemistry of the Nile tilapia, Oreochromis niloticus (Linnaeus, 1757) under the impact of water pollution. Aquat Ecol 2002, 36:549-557.

32. Cameron JS: Kidney failure: the facts. New York: Oxford University Press; 1996. $78 \mathrm{pp}$.

33. Srivastav AK, Srivastava SK, Srivastav SK: Impact of deltamethrin on serum calcium and inorganic phosphate of freshwater catfish, Heteropneustes fossilis. Bull Environ Contam Toxicol 1997, 59:841-846.

34. Ansari RA, Kaur M, Ahmad F, Rahman S, Rashid H, Islam F, Raisuddin S: Genotoxic and oxidative stress-inducing effects of deltamethrin in the erythrocytes of a freshwater biomarker fish species, Channa punctata Bloch. Environ Toxicol 2009, 24:429-436.

35. Glickman $A H$, Weitman SD, Lech JJ: Differential toxicity of trans-permethrin to rainbow trout and mice. I. Role of biotransformation. Toxicol Appl Pharmacol 1982, 66:153-161.
36. Filho DW: Fish antioxidant defences- a comparative approach. Braz J Med Biol Res 1996, 29:1735-1742.

37. Kochhann D, Pavanato MA, Llesuy SF, Correa LM, Konzen Riffel AP, Loro VL, Mesko MF, Flores EM, Dressler VL, Baldisserotto B: Bioaccumulation and oxidative stress parameters in silver catfish (Rhamdia quelen) exposed to different thorium concentrations. Chemosphere 2009, 77:384-391.

38. Pandey S, Ahmad I, Parvez S, Bin-Hafeez B, Haque R, Raisuddin S: Effects of endosulfan on antioxidants of freshwater fish Channa punctatus Bloch: 1- protection against lipid peroxidation in liver by copper preexposure. Arch Environ Contam Toxicol 2001, 41:345-352.

39. Sayeed I, Ahmad I, Fatima M, Hamid T, Islam F, Raisuddin S: Inhibition of brain $\mathrm{Na}^{+}, \mathrm{K}^{+}$-ATPase in freshwater fish (Channa punctatus Block) exposed to paper mill effluent. Bull Environ Contam Toxicol 2000, 65:161-167.

40. Svobodova Z, Luskova V, Darastichova J, Svoboda M, Zlabek V: Effect of Deltamethrin on haematological indices of common carp. Acta Vet Brno 2003, 72:79-85.

41. Manna S, Bhattacharyya D, Mandal TK, Das S: Repeated dose toxicity of alfa-cypermethrin in rats. J Vet Sci 2004, 5:241-245.

42. Bradberry SM, Cage SA, Proudfoot AT, Vale JA: Poisoning due to pyrethroids. Toxicol Rev 2005, 24:93-106.

43. Elia AC, Galarini R, Taticchi MI, Dorr AJ, Mantilacci L: Antioxidant responses and bioaccumulation in Ictalurus melas under mercury exposure. Ecotoxicol Environ Saf 2003, 55:162-167.

doi:10.1186/1746-6148-8-45

Cite this article as: Amin and Hashem: Deltamethrin-induced oxidative stress and biochemical changes in tissues and blood of catfish (Clarias gariepinus): antioxidant defense and role of alpha-tocopherol. BMC Veterinary Research 2012 8:45.

\section{Submit your next manuscript to BioMed Central and take full advantage of:}

- Convenient online submission

- Thorough peer review

- No space constraints or color figure charges

- Immediate publication on acceptance

- Inclusion in PubMed, CAS, Scopus and Google Scholar

- Research which is freely available for redistribution 